March - 2010

\title{
Learning in an Online Distance Education Course: Experiences of Three International Students
}

\author{
Zuochen Zhang \\ University of Windsor, Canada \\ Richard F. Kenny \\ Athabasca University, Canada
}

\begin{abstract}
This case study explores the learning experiences of three international students who were enrolled in an online master's program offered by a large university in Canada. The aim of the study was to understand the international students' experiences with, and perspectives on, the online learning environment. Findings indicate that previous education and especially language proficiency strongly impacted the learning of these students in this environment. Non-native English speakers required considerably more time to process readings and postings and to make postings themselves. Their lack of familiarity with the details of North American culture and colloquial language made it difficult to follow much of the course discussions. They also tended to avoid socializing in the course, which left them at the periphery of course activities. Based on these findings, the authors make the following recommendations for designers and instructors of online courses: 1) Raise the English language proficiency requirement for graduate admissions into online programs because the text-based communication in a CMC space requires interpreting messages without non-verbal cues; 2) Ensure that online distance education course designers are aware of the needs and expectations of international students; and 3) Combine the design principles from both traditional and constructivism theories.
\end{abstract}

Keywords: Distance education; online learning; CMC; international students

\section{Background to the Study}

As new technologies become less expensive and various forms of multimedia are increasingly accessible, online learning environments are becoming widely used for teaching and learning purposes. In particular, online education, as experienced through computer-mediated communication (CMC), is being heralded as meeting the needs of course participants' lifestyles by allowing them to juggle personal commitments, to manage time conflicts, and to access course materials from a variety of locations. 
The benefits of asynchronous communication via CMC have the potential to enhance cooperative learning by providing users with extended time (Aviv, 2001). Participants in an online learning environment can engage in course discussions by providing reflections after thinking about what has been said (Bird, 2004). As asynchronous communication may also allow course participants more time for reading, writing, and posting in discussion forums, there is the potential to increase their participation. Moreover, this virtual environment may promote critical thinking that leads to higher achievement and more satisfaction in collaborative learning (Alavi, 1994).

Stahl (2005) posited that learning takes place in effective collaborative interactions and that individuals internalize the effects of collaboration. However, it has been argued that effective collaboration will not take place in an online learning environment unless the instructor takes proactive measures to provide an appropriate context for collaborative learning (Harasim, 1989). The increasing globalization of education makes it necessary for educators to be aware of the factors beyond their institutions that constrain, steer, or facilitate their practice (Bottery, 2006) and to avoid ethnocentric instructional designs (Gayeski, Sanchirico, \& Anderson, 2002).

\section{Literature Review}

\section{Computer-Mediated Communication (CMC) and Online Learning}

December (2009) defines CMC as "the process by which people create, exchange, and perceive information using networked telecommunications systems (or non-networked computers) that facilitate encoding, transmitting, and decoding messages.” CMC provides both the technological infrastructure for, and permits the human cognitive processes involved with, communication and learning. CMC can take place in an evolving range of both synchronous and asynchronous digital spaces. Some advantages of asynchronous communication (e.g., email or threaded discussion forums) include the flexibility to log on from various geographic locations and the opportunity for reflection before responding to a classmate's or the instructor's posting (Everhart, 2000). However, some asynchronous communication methods can also adversely affect course participants if they feel that they are being left behind or if they experience information overload. For instance, students who do not receive a prompt response to their postings or those who find more postings than they can manage to find time to read may feel lonely or stressed.

CMC spaces can also provide a social system for learning. Palloff \& Pratt (1999) have shown that learning is improved when there is a sense of community established through the use of CMC. When new members join communities of practice, they have access to existing members and learn from them as they work (Lave \& Wenger, 1991). In a virtual learning community, meaning can be negotiated among learners through a process of discussion and collaborative work on specific group projects. Moreover, the interaction among individuals through CMC may assist learners in developing a meaningful and strong sense of identity (Postmes, Spears, \& Lea, 2000). For example, Biesenbach-Lucas (2003) observes that while non-native and less verbal students tend to keep silent in face-to-face class, they "felt more comfortable participating more fully in electronic discussions” (p. 36). 
In addition, in recent years, online education has experienced the strong influence of constructivist learning theory and a paradigm shift from teacher-controlled to learner-centred instruction (Peters, 2002). In such a constructivist learning environment, learner autonomy and initiative is accepted and encouraged. Learners acquire knowledge by fitting new information together with what they already know. Hence learning is affected by the social and cultural contexts of the situation (Vygotsky, 1978) and the beliefs and attitudes of the learner. Learners are encouraged to invent their own solutions, try out ideas and hypotheses, and assemble new knowledge from their prior experiences (Hedberg \& Harper, 1997).

\section{Culture and CMC Environments}

In contrast to face-to-face instruction, online learning environments allow geographically dispersed students to enrol in courses; thus, online learners are more likely to be exposed to a greater variety of learning experiences, including those that reflect different cultural conditions and expectations. Ziegahn (2001) suggests that it is important for designers of adult learning programs to take cultural differences into account.

Learners' cultural conditions are influenced by the dynamics of social forces as they operate multidimensionally and multidirectionally across both the micro environment of the immediate locale and the macro environment of the learner's societal situation. The flow and circulation of social, economic, technological, and political forces is complex in any society (Fiske, 1992). Wild and Henderson (1997) argue that culture has a very strong influence on the management, design, and use of information, communication, and learning systems. Palloff and Pratt (1999) suggest that a CMC environment is the great equalizer, which renders participants' cultural, ethnic, or social condition irrelevant, but Reushle and McDonald (2000) disagree, arguing that with the globalization of learning the design process for online teaching and learning must consider and accommodate the challenges of changing learner profiles caused by increasing enrolments of students from diverse conditions.

In this regard, it is becoming common practice in higher education for online distance education programs to enrol international and transnational students. These programs are often offered in a country other than where the awarding institution is located and involve students who have had different teaching and learning experiences and expectations. McLoughlin (2000) argues that as the current instructional design models are the products of particular cultures, they usually do not fully contextualize the learning experience. Since web-based instruction is based on the particular epistemologies, learning theories, and goal orientations of the designers themselves, it cannot be expected to be culturally neutral. Wild and Henderson (1997) state that the learning theories that play a dominant role in distributed learning systems currently provided on the Internet are likely to avoid "the cognitive, epistemological and philosophical aspects of interrelated cultural educational contexts” (p. 187). 


\section{Constructivist Theory and Cultural Differences}

Online distance education courses that are designed based on principles derived from social constructivist theories of learning usually incorporate teaching strategies that require learners to collaborate, communicate, explore, and reflect (Lebow, 1993). Learning is viewed in these perspectives as an active, constructive process through which the learner creates new knowledge based on available cognitive resources by extracting information from the environment and integrating it with the information stored in memory (Nathan \& Robinson, 2001); thus, it follows that constructivist and collaborative approaches are the most appropriate modes for managing online discussion groups (Oren, Mioduser, \& Nachmias, 2002).

Regardless, when applying constructivist principles in online distance education course design, it is important to consider whether these design principles fit the perspectives and expectations of students with different cultural conditions. For example, in Asian countries such as China, though the education system has been greatly influenced by Western pedagogical theories in the past few decades, and increasingly attention is being paid to the development of learners' problem solving and communication skills in different educational settings, mainstream educational programs are still test-driven (Lee, 2004). Learners' expectations of a course, whether face-to-face or online, tend to be focused on the mastery of content for the course and on obtaining high scores on the tests.

Active participation in course activities is a very important part of online learning (Scheuermann, Larsson, \& Toto, 2001). Researchers have studied how to motivate online learners to actively participate, for example, by providing incentives and by making participation a part of evaluation. However, Beaudoin's (2002) study shows that “invisible” online students, those who do not seem to be participating as often as others, may log on to the course site often and "feel they are still learning and benefiting from this low-profile approach to their online studies” (p. 147). An online learning environment has many benefits for learners, such as flexibility, the quantity and quality of participation, open and accessible communication, and archived postings from participants for reference (Morse, 2003). However, as students enrol in online courses from different locations, time zone differences may keep some students from participating, especially when synchronous communication methods are used (Cifuentes \& Shih, 2001). Research also shows that learners may feel uncertain in their communication and isolated in this environment because of a lack of non-verbal cues and social presence (Muilenburg \& Berge, 2005), and this may impact significantly students who were raised in a culture where social context and/or social presence (Ku \& Lohr, 2003; Tu, 2001) are emphasized. International students, especially those who are from Asia and the Middle East, may face more challenges or frustrations in this regard than their domestic peers because of such factors as language barriers (Goodfellow, Lea, Gonzalez, \& Mason, 2001; Lee \& Greene, 2007), feelings of isolation or alienation (Shattuck, 2005; WalkerFernandez, 1999, as cited in Uzuner, 2009), unfamiliarity with the disciplinary culture of the institution offering the course (Zhao \& McDougall, 2008), and a lack of knowledge of specific cultural references (Thompson \& Ku, 2005). Influenced by their home culture, international students may not participate in the online learning environment as actively as domestic students (Al-Harthi, 2005; Hannon, J., \& D’Neto, 2007). 
This study explores the learning experiences of three international students enrolled in an online master's program offered by a large university in Canada with the aim of understanding their perspectives of the online learning environment. Based on our findings, we make some tentative recommendations for designers and instructors of online courses about how to take cultural expectations into account and how to accommodate the needs and perspectives of such international students.

\section{Methods}

\section{Purpose}

The purpose of this study was to explore the learning experiences of three international online master's students by using an exploratory case study design to understand their perspectives of the online learning environment. The goal of an exploratory case study is "not to conclude a study but to develop ideas for further study" (Yin, 2003, p. 120). A case study "provides descriptions of a case, a group, a situation, or an event" (Krathwohl, 1998, p. 26) and examines the details of a setting, subject, or particular event (Merriam, 1988; Stake, 1995; Yin, 2003). We examined relationships between a research participant's cultural conditions and his/her learning practices as complex social phenomena (Yin, 2003) in order to provide a "comprehensive view and broader insight into the multifaceted phenomenon” (Waggoner, 1991, p. 137). In this case study, we combined both qualitative and quantitative research methods (Waggoner, 1991).

\section{Research Questions}

This study addressed the following two research questions:

1) How do international students perceive their learning in an online course?

2) What were the biggest challenges the international students had to face in the online learning environment?

\section{Participants}

The participants in the full study included 12 graduate students enrolled in a graduate Educational Technology program offered fully online at a large western Canadian university. The course was 13 weeks long, and WebCT was used as the course delivery system. To recruit participants, a contact letter was sent through the instructors to all 55 students in the course. Thirteen students volunteered to participate in the study, but one decided to withdraw after a few weeks. Participants' ages ranged between 20 and 50, and there were nine females and three males. The participants represented a variety of backgrounds in terms of first language, country of origin, previous educational experiences, life experience in North America, English language proficiency, types of employment, access to learning technologies, and reasons for enrolling in the program. Most of the participants were located in western Canada while four lived outside of Canada: two in Japan, one in China, and one in the United States. Additional information about 
the participants/course/course instructor(s)/program of study is omitted to protect their privacy. Among the twelve participants, eight were born in countries other than North America, but they had lived in Canada or the USA for more than eight years. As such, they had been substantially exposed to the educational system and culture in North America. This case study focuses on the experiences of three international students. Ping, Masahiro and Mitra are non-native speakers of English, who had not lived in North America for more than six months. They were taking the course from China, Japan, and Canada respectively.

\section{Data Collection}

Data were collected through the use of an online survey, online observation, email interviews, and telephone interviews. The online survey was used to collect demographic data, such as age, access to the Internet, educational background, English proficiency, gender, and life experience in North America. The first author made observations in the online discussion forums by monitoring how often the participants were posting messages, how promptly they responded to the course assignments, how long their postings were, how formal their language was, and how their peers responded to their postings. Email interview questions were generated on the basis of the survey results and observations then sent to participants individually. We asked participants about their cultural conditions of learning and any modifications they made for the course. Further, semistructured interviews were conducted by telephone to obtain an in-depth understanding of the participants' perspectives of online learning and their experiences in an online learning environment.

\section{Data Analysis}

The research data were analyzed to understand the participants' learning experiences in an online learning environment and how their cultural conditions affected their participation in the learning process. The analysis was carried out by the first author, who used multiple methods to code the data. After reading all the observation notes and transcripts from the discussion forums, he first used open coding (Creswell, 2003) to mark participants' postings with regard to a) kinds of questions they raised, b) how often and when they participated online, c) if and how they articulated arguments and the responses these arguments received, d) how they responded to peer messages, and e) their perspectives and interpretations of different aspects of the course. Next, he used a holistic coding approach (Spatariu, Hartley, \& Bendixen, 2004) to analyze the interview transcripts, looking at the most frequently used keywords and key terms (e.g., challenge, frustration, language, background knowledge). Finally, he identified themes related to the research questions and looked for relationships to the key concepts of learning experiences and cultural conditions as they emerged from the data and as they were associated with the literature reviewed.

Through the data analysis, he interwove the empirical data with the conceptual and theoretical ideas discussed in the literature review as a way to examine the contexts of these data within the broader scope of selected research. He also read through the postings looking for what themes emerged while the collection of other data was still in process. For example, the recording and 
reading of discussion postings aided in the construction and modification of telephone interview questions for different interviewees.

The analysis of quantitative data for the purpose of generating statistical information was carried out at the end of the course semester, while qualitative data collection commenced at the beginning of the course and was ongoing for the duration of the study. This research data was then reanalysed to focus on the three international students described in this article, using the themes of previous educational experiences, English language proficiency, life experiences, and socializing in the online learning environment, which are most closely related to the online learning experiences of these participants.

\section{Findings}

\section{Previous Educational Experiences}

Participants in this research study had a wide variety of previous educational experiences. We focused on whether their previous education was received outside of North America or had occurred within North America because the course they had enrolled in was offered through a North American university. We assumed that their learning would also be affected by whether they had learning experiences in an online environment or if they had previously experienced courses that were organized around a constructivist curriculum. The three international students focused on in this study had all received their degrees in their home country. Ping received her bachelor's and master's degrees in Science from China, Masahiro received his Bachelor of Science from Japan, and Mitra received her Bachelor of Science from Iran. They all had online experiences prior to this course.

Ping believed the relationship between professors and graduate students was closer in her previous degree in China than in the current online program and the topics of graduate students' conversations were usually related to research rather than social interaction:

I got more advising from professors than in this online program. The learning environments are also different. Even when it was out of classroom or lab, the conversations with professors or other graduate students were mostly related to research. We often talked about newly released technologies or software in the dining hall. In this online environment, when you are not online, you are on your own. (Ping, telephone interview)

Masahiro observed that the Japanese and Canadian education systems were quite different in terms of allowing students to have discussions in class. The Japanese curriculum is test-driven, and students are supposed to memorize what they learned from the textbook to pass tests. So, when he started taking the online master's program offered in Canada, it took him some time to become familiar with these different ways of teaching and learning: 
[In Japan], because we have the objectives, we want students to pass the qualification test, or license test. ...So [teaching is] more like pushing knowledge into their brains. Is there talking, or is there discussing during the class? It's not acceptable in Japan. No chatting during the class. You know what I mean, silence. Only the instructor's voice or students' voice if they are asked to answer. (Masahiro, telephone interview)

Mitra said that she had taken an online professional development course previously, but because there were a number of moderators in that course, she found it more supportive than this graduate course. In her undergraduate program, all the courses were taught face-to-face, and she felt insecure in this online environment because of the lack of nonverbal cues:

In this online setting, you say something, either you get some responses and you don't know what are the emotions behind it, or you do not get any response, and what does that mean? ... so I sometimes decided to have less contributions, because I was scared, if I say something and these people think that "She's an idiot.” (Mitra, face-to-face interview)

Previous educational experiences also affected the participants' understanding and perspectives of their learning environment. For example, Ping and Masahiro stated that one of the main reasons they did not seem to be as active as many other classmates was that they were reluctant to argue with their peers, let alone the instructors, because of their prior educational experiences and societal sets of cultural conditions. Research (e.g., Bates \& Poole, 2003) shows that in many Asian countries, the educational systems reflect a hierarchical authoritative structure of pedagogy. Ping and Masahiro had received their previous education in China and Japan respectively, where a transmission approach to teaching and learning is still widely used and valued by teachers (Pratt, Kelly, \& Wong, 1999).

\section{English Language Proficiency}

Admission into this graduate program required that students first demonstrate both verbal and written proficiency in the use of English. However, non-native English speakers, especially those whose written and verbal skills met a minimal level of proficiency, were apt to think the language barrier prevented them from posting as many messages as they would have liked. During their telephone interviews, Ping and Masahiro expressed difficulties they experienced when learning through a CMC system.

Masahiro thought his English was sufficient for daily conversations, but reading and writing in English required a great deal of time:

I am actually taking this course in a second language, and my [English] language, speaking, oral communication is not so bad, 
but reading and writing, especially writing, are actually pretty slow. And also I have to write with hand as well as type the words on computers. And spelling mistakes, sometimes I have to check the spelling and stuff, so it takes a lot of time. (Masahiro, telephone interview)

He used email with a spell check function and was diligent about proofreading his communication texts before posting. He relayed to us that he was worried that his peers might refuse to work with him in group activities if they judged his English proficiency as poor. Masahiro stated,

Actually I usually use email that has spell checker. I don't write down my postings real-time. I always use those spell check editor, and then copy and paste, so it takes more time. Sometimes I ask my wife [a native English speaker from Canada] to check the grammatical stuff, but when I don't have time, I directly write. I always worry about my English writing. My writing is not so good so other people might don't [not] want to work with me, especially for group assignments. (Masahiro, telephone interview)

Like Masahiro, Ping also experienced language difficulties as a non-native speaker. She stated that it was difficult for her to understand her peers' postings, especially if informal language was used, and the language barrier kept her from responding to others' postings:

... language difficulties restricted my ability to learn. The difficulties I faced to were my slow reading and writing speed and had difficulties in understanding the slang and idioms in other's posts as well as the meaning behind their posts. These difficulties made me busied [busy] in reading materials and my peers' posts so that I seldom responded to other's posts even if I had read them and had some ideas in my mind. (Ping, email interview)

However, she thought it was easier to communicate in the online learning environment because, compared with face-to-face courses, the online environment made her feel less stressed or embarrassed when communicating with classmates in English:

I feel the online environment is better for ESL students, especially to those [who] are not at home in English. [In an online course] I can spend more time on reading, and I think it easier to read than to listen. And after reading threads of discussions I can figure out what it's about. ...in an online class, you don't have to worry too much about your English so you are 
less nervous. ... I feel more relaxed, I can spend more time on it but I don't have to worry about being embarrassed. (Ping, telephone interview)

Mitra was quite comfortable with both spoken and written English, but she still found it hard to understand many postings from her classmates that involved some Western specific cultural background knowledge she was lacking. She said,

I was not able to make sense of what I was reading because it was very context specific. Everything was deeply rooted in western culture which is very, very much different from mine. People were writing essays about things that I did not know what they meant. (Mitra, email interview)

She also felt hesitant to post as many messages as she would have liked to because she was afraid that the others would not understand what she meant.

\section{Life Experiences}

Besides previous educational experiences, life experiences (including living and work experiences) also played a role in influencing the way the participants communicated with their peers and the instructors. For example, when Ping first enrolled in the online program, she tried to contact those with Chinese names or whose photograph on the self-introduction "looked Chinese" because she thought it would be easier to communicate with them in terms of language and culture values. But she found it hard to tell someone's first language simply by their name or appearance as many people in the course, even though their ethnic heritage was Chinese, were born and grew up in an English-speaking country and did not speak Chinese. So she started to communicate with colleagues who posted messages that reflected her opinions or with those who responded to her postings, no matter what their ethnic background was.

Masahiro was a high school teacher in Japan, who had to leave for school early in the morning and stay after school to run a computer programming club for students or to attend staff meetings. So the only time he could study for his online course was late at night, when his family members were asleep. In the online course, synchronous discussions were held every Thursday, and two sessions were held to accommodate the different schedules or time zones of class members, one in the morning and the other in the afternoon. For Masahiro, neither of the sessions worked because of the 17-hour time difference and his work schedule. During the interview, Masahiro said that he did not want to skip the graded synchronous discussions, but he was not able to attend, so he had to accept a lower mark. 


\section{Socializing in the Online Learning Environment}

The online course had a space called "Socializing/Mingling," which was set up by the instructors for course members to communicate on topics not directly related to the course content. Many messages were posted in this space by the course members, mostly to share jokes or information about upcoming conferences or to make arrangements for face-to-face group meetings for those who resided nearby. However, the three participants for this case study did not make much use of the space. Masahiro posted three short messages in this space, mostly to ask questions about class assignments, but Mitra and Ping did not post any messages in this space. When asked about their perspectives on the socializing space, the three participants said they went there occasionally to see what was posted, but they did not really make any contributions as this space was not directly related to the learning of the course content. Masahiro said he posted messages there because he felt it was "less embarrassing" as he did not know under which other specific thread he should have posted his questions.

\section{Discussion}

English language proficiency was one of the most important cultural conditions related to the participants' learning practices in this online learning environment and was by far the most restricting condition for the participants. Language proficiency affected their participation and communication in course discussions. Non-native speakers of English were not very confident about their English proficiency and spent considerably more time than their English-speaking peers reading and composing messages in the course CMC spaces. They preferred to read others' postings first rather than initiate a message about the assigned readings, and some chose to have others proofread their drafts before they were posted on the bulletin board. For example, Masahiro believed that he was a slow reader, and to save time he preferred to read short postings in the discussion forum first and to read longer ones when he found time later. Ping talked about her difficulties understanding the passages from peers, especially the colloquial expressions.

Masahiro also equated his own sense of identity and productivity with his ability to use the English language proficiently enough to communicate with his peers in the course. This indicates that he understood that his use of the English language partially represented who he was to peers in the context of the CMC spaces, which had the potential to regulate (limit or extend) his ability to be productive in the course. Both Masahiro and Ping stated that in their previous educational experiences if they agreed with a peer's opinion, they were not motivated to respond. Both were also reluctant to argue with peers in a public forum if they did not agree with somebody's opinion. This supports the assertion of Biesenbach-Lucas (2003) that "non-native speakers, particularly students from Asian countries, consider it far less appropriate to challenge and criticize ideas, and in addition, they may not know how to express disagreement appropriately in English” (p. 37).

Mitra had confidence in her command of English but stated that she had difficulties communicating with peers on the discussion board about certain topics. This echoes the findings 
of other researchers (e.g., Thompson \& Ku, 2005) that a lack of knowledge of certain cultural references may frustrate international students.

In this online learning environment, all communication between the instructors and course members and among course members themselves took place via CMC. With asynchronous discussions, participants usually waited for a response to their postings. For some non-native English speakers, these communication delays produced nervousness, adding to their sense of apprehension about their own ability to contribute in a meaningful way to the course. Some assumed that if their posting did not get a response, it might mean they did not express themselves clearly or that their message was interpreted as offensive. There was a sense of anxiety associated with using a CMC space for non-English language speakers. Personal interests might be an explanation for some participants' passive participation in course CMC spaces, but for non-native English speakers, the degree of their activity was based on their language proficiency and their ability (Lee \& Greene, 2007) to control their communication practices in the online learning environment.

Research participants with different cultural conditions perceived collaborative learning differently. The participants who had limited North American educational experiences tended to think that other course members were more knowledgeable. This belief inhibited their confidence to express their thoughts in English freely, and it made them unwilling to engage in CMC spaces and to negotiate course issues with other group members. These participants believed that the communications in the online learning environment should be closely related to the learning of the course contents, so even though some course members thought a space for socializing was somewhat important, they did not perceive it as critical for their learning. In addition, life experiences extend or limit learners' participation and engagement in the online learning community. For example, when Ping found that those who "looked Chinese" were not actually Chinese speakers she changed her way of approaching her colleagues. She may have done so because she felt that her original approach did not help her to find the social context she was seeking (Ku \& Lohr, 2003). And finally, as discussed by Cifuentes and Shih (2001), time zone differences can limit some learners' access or participation. Masahiro's work schedule and time zone kept him from attending the synchronous discussions even though he did not want to lose points for his absence.

Based on the number of postings from each student in this online learning environment, it is clear that international students were more often than not "invisible" online, or "lurkers," who did not seem to be participating as often as others. Beaudoin (2002) believed that these students "feel they are still learning and benefiting from this low-profile approach to their online studies" (p. 147). We suspect that their previous cultural conditions "nurtured" them to be listeners rather than active speakers in class. 


\section{Conclusions}

Various cultural attributes related to the online learning environment have been identified in this study. However, English language proficiency was one of the most important cultural attributes that limited or extended course members' participation within the CMC spaces. Admission into graduate studies at this particular university requires all non-native English speakers to score 550 or above on the TOEFL (Test of English as a Foreign Language), and scores of this magnitude (or the equivalent 6.5-7.0 rating on the IELTS, the International English Language Testing System) are predictive of academic success at this level (Feast, 2002; Messner \& Liu, 1995). However, these minimum scores might not be sufficient for admission of students to online distance education programs. In this study, some of the research participants who scored close to the minimum TOEFL score still found it difficult to complete and maintain a minimum level of participation. For example, Masahiro's TOEFL score was 580 and, in addition, his (native English-speaking) Canadian wife helped him with the understanding of readings and the proofreading of his writing. Nonetheless, he still had difficulties completing the course assignments and engaging comfortably with online discussions. Raising the English language proficiency requirement for graduate admissions into online programs, therefore, might be in order because the text-based communication in a CMC space requires interpreting messages without non-verbal cues.

This research indicated that the CMC spaces of this online learning environment were contested educational landscapes. Virtual spaces are connected to real life cultural conditions of the students enrolled in the course. Some research participants were reluctant to engage in course discussions because they were not sure what they could contribute. They were not from North America and lacked certain background knowledge. They understood that their textual communications partially represented who they were. The design and delivery of the online course were focused on what was familiar for local students, and students with strong English language proficiencies and Western cultural backgrounds tended to dominate the discussion forums. In light of the fact that an online course can enroll members from different parts of the world with different educational and life experiences, course designers and instructors have a responsibility to develop course content and mediate CMC spaces to accommodate the cultural conditions of these diverse populations. In order to meet the needs of learners who are used to certain educational practices, it may be necessary for online distance education course designers to be aware of the needs and expectations of international students and to combine the design principles from both traditional and constructivism theories, at least during a period of transition of education paradigms. 


\section{References}

Alavi, M. (1994). Computer-mediated collaborative learning: An empirical evaluation. MIS Quarterly, 18(2), 159-174.

Al-Harthi, A. S. (2005). Distance higher education experiences of Arab Gulf students in the United States: A cultural perspective. The International Review of Research in Open and Distance Learning, 6(3). Retrieved from http://www.irrodl.org/index.php/irrodl/article/view/263

Aviv, R. (2001). Educational performance of ALN via content analysis. Journal of Asynchronous Learning Networks, 4(2), 53-72. Retrieved from http://www.aln.org/publications/jaln/v4n2/pdf/v4n2_aviv.pdf

Bates, A.W., \& Poole, G. (2003). Effective teaching with technology in higher education: Foundations for success. San Francisco, CA: Jossey-Bass.

Beaudoin, M. (2002). Learning or lurking? Tracking the "invisible" online student. Internet and Higher Education, 5, 147-155.

Biesenbach-Lucas, S. (2003). Asynchronous discussion groups in teacher training classes: Perceptions of native and non-native students. JALN, 7(3), 24-46.

Bird, C. (2004). Sinking in a C-M sea: A graduate student's experience of learning through asynchronous computer-mediated communication. Reflective Practice, 52(2), 253-263.

Bottery, M. (2006). Education and globalization: Redefining the role of the educational professional. Educational Review, 58(1), 95-113.

Cifuentes, L., \& Shih, Y.C. D. (2001). Teaching and learning online: A collaboration between U.S. and Taiwanese students. Journal of Research on Computing in Education, 33, 456474.

Creswell, J.W. (2003). Research design: Qualitative, quantitative and mixed methods approaches. Thousand Oaks, CA: Sage.

December, J. (2009). What is computer-mediated communication. Retrieved from http://www.december.com/john/study/cmc/what.html

Everhart, R. (2000). Enterprise systems and distance learning: Creating services for connected learners. Syllabus, 13(9), 48-51.

Feast, V. (2002). The impact of IELTS scores on performance at university. International Education Journal, 3(4), 70-85. 
Fiske, A.P. (1992). The four elementary forms of sociality: Framework for a unified theory of social relations. Psychological Review, 99(4), 689-723.

Gayeski, D., Sanchirico, C., \& Anderson, J. (2002). Designing training for global environments: Knowing what questions to ask. Performance Improvement Quarterly, 15(2), 15-31.

Goodfellow, R., Lea, M., Gonzalez, F., \& Mason, R. (2001). Opportunity and e-quality: Intercultural and linguistic issues in global online learning. Distance Education, 22(1), 65-84.

Hannon, J., \& D’Neto, B. (2007). Cultural diversity online: Student engagement with learning technologies. International Journal of Educational Management, 21(5), 418-432.

Harasim, L. (1989). On-line education: A new domain. In R. Mason \& A. Kaye (Eds.), Mindware: Communication, computers and distance education (pp. 50-62). Oxford, UK: Pergamon.

Hedberg, J., \& Harper, B. (1997). Creating motivating interactive learning environments. Keynote Address, EDMEDIA, Calgary, Canada.

Krathwohl, D. (1998). Methods of educational and social science research: An integrated approach ( $2^{\text {nd }}$ ed.). New York: Addison-Wesley Educational Publications, Inc.

Ku, H. Y., \& Lohr, L. L. (2003). A case study of Chinese students' attitudes toward their first online learning experience. Educational Technology Research and Development, 51(3), 95-102.

Lave, J., \& Wenger, E. (1991). Situated learning: Legitimate peripheral participation. New York: Cambridge University Press.

Lebow, D. (1993). Constructivist value for instructional systems design: Five principles toward a new mindset. Educational Technology Research and Development, 41(3), 4-16.

Lee, D. (2004). Web-based instruction in China: Cultural and pedagogical implications and challenges. Educational Technology Research and Development, 52(1), 101-105.

Lee, Y., \& Greene, J. (2007).The predictive validity of an ESL placement test: A mixed methods approach. Journal of Mixed Methods Research, 1(4), 366-389.

McLoughlin, C., \& Oliver, R. (2000). Designing learning environments for cultural inclusivity: A case study of indigenous online learning at tertiary level. Australian Journal of Educational Technology, 16(1), 58-72. 
Merriam, S. (1988). Case study research in education: A qualitative approach. San Francisco, CA: Jossey-Bass Inc., Publishers.

Messner, P.E., \& Liu, N. (1995). The Test of English as a Foreign Language: An examination of "cut-off scores" in US universities. The International Journal of Educational Management, 9(2), 39-42.

Morse, K. (2003). Does one size fit all? Exploring asynchronous learning in a multicultural environment. JALN, 7(1), 37-55.

Muilenburg, L.Y., \& Berge, Z.L. (2005). Student barriers to online learning: A factor analytic study. Distance Education, 26(1), 29-48.

Nathan, M., \& Robinson, C. (2001). Considerations of learning and learning research: Revisiting the “media effects” debate. Journal of Interactive Learning Research, 12(1), 69-88.

Oren, A., Mioduser, D., \& Nachmias, R. (2002). The development of social climate in virtual learning discussion groups. International Review of Research in Open and Distance Learning, 3(1). Retrieved from http://www.irrodl.org/content/v3.1/mioduser.pdf

Palloff, R.M., \& Pratt, K. (1999). Building learning communities in cyberspace: Effective strategies for the online classroom. San Francisco, CA: Jossey-Bass Publishers.

Peters, O. (2002) Distance education in transition. Oldenburg, Germany: Bibliotheks-und Informationssystem der Universität Oldenburg.

Postmes, T., Spears, R., \& Lea, M. (2000). The formation of group norms in computer-mediated communication. Human Communication Research, 26(3), 341-371.

Pratt, D.D., Kelly, M., \& Wong, W.S.S. (1999). Chinese conceptions of “effective teaching' in Hong Kong: Towards culturally sensitive evaluation of teaching. International Journal of Lifelong Education, 18(4), 241-258.

Reushle, S., \& McDonald, J. (2000). Web-based student learning: Accommodating cultural diversity. Indian Journal of Open Learning, 9(3), 351-359.

Scheuermann, F., Larsson, K., \& Toto, R. (2001). Designing collaborative teaching and learning in virtual environments for large scale international participation. Proceedings of EDMedia 2001 World Conference on Educational Multimedia, Hypermedia \& Telecommunications, Finland, 1655-1660.

Shattuck, K. (2005). Cultures meeting cultures in online distance education: Perceptions of international adult learners of the impact of culture when taking online distance 
education courses designed and delivered by an American university (Unpublished doctoral dissertation). The Pennsylvania State University.

Spatariu, A., Hartley, K., \& Bendixen, L. (2004). Defining and measuring quality in online discussions. The Journal of Interactive Online Learning, 2(4).

Stahl, G. (2005). Group cognition in computer-assisted collaborative learning. Journal of Computer Assisted Learning, 21(2), 79-90.

Stake, R.E. (1995). The art of case study research. Thousand Oaks, CA: Sage Publications, Inc.

Thompson, L., \& Ku, H. (2005). Chinese graduate students' experiences and attitudes toward online learning. Educational Media International, 42(1), 33-47.

Tu, C. (2001). How Chinese perceive social presence: An examination of interaction in online learning environment. Educational Media International, 38(1), 45-60.

Uzuner, S. (2009). Questions of culture in distance learning: A research review. The International Review of Research in Open and Distance Learning, 10(3). Retrieved from http://www.irrodl.org/index.php/irrodl/article/view/690

Vygotsky, L. S. (1978). Mind in society: The development of higher psychological processes. M. Cole, V. John-Steiner, S. Scribner, \& E. Souberman (Eds.). Cambridge, MA: Harvard University Press.

Waggoner, M. (1991). A case study approach to evaluation of computer conferencing. In A.R. Kaye (Ed.), Collaborative learning through computer conferencing (pp. 137-146). Berlin: Springer-Verlag.

Walker-Fernandez, S. E. (1999). Toward understanding the study experience of culturally sensitive graduate students in American distance education programs (Unpublished doctoral dissertation). Florida International University.

Wild, M., \& Henderson, L. (1997). Contextualizing learning in the World Wide Web: Accounting for the impact of culture. Education and Information Technologies, 2(3), 179-192.

Yin, R. (2003). Case study research: Design and methods ( $3^{\text {rd }}$ ed.). Thousand Oaks, CA: Sage Publications, Inc.

Zhao, N., \& McDougall, D. (2008). Cultural influences on Chinese students' asynchronous online learning in a Canadian university. Journal of Distance Education, 22(2), 59-80.

Ziegahn, L. (2001). Considering culture in the selection of teaching approaches for adults. ERIC Digest, 231. Retrieved from http://www.cete.org/acve/docs/dig231.pdf 


\section{Appendix A}

\section{Online Survey}

Please answer the following questions and then hit the "Submit" button:

\section{Name:}

2. Gender

Female

Male

\section{Age range:}

$20-29$

$30-39$

$40-49$

$50+$

\section{Online learning experience}

This is my first online course

This is my second online course

I have taken three or more online courses before this one

\section{English language proficiency}

English is my native language

English is not my first language but I've been using English since secondary school

English is not my first language, but it was my major in college/university

I started to use English for academic purposes since I came to Canada (or another Englishspeaking country)

Other. Please explain:

\section{Education background}

This MET program is my first Master's program

This is my second Master's program

I'm enrolled in this course just for credits for another program

Other. Please explain:

\section{Life experience in North America}

I was born and grew up in Canada / USA

I came to Canada / USA ten or more years ago

I've lived in Canada / USA for three or less than three years

Other. Please explain:

\section{Internet access from home}

Dia-up

ADSL/Cable

No access from home 


\section{Appendix B}

\section{Email Interview Questions}

1. Describe your learning in an online environment. Please include the following: physical setting, amount of and use of time, influence of family life, work, or other aspects of your social situations. In particular describe how these social conditions enhance or restrict your ability to learn.

2. Describe ways that you modify your social situations to enhance your preferred ways of learning in an online environment. Please take into consideration the same social conditions mentioned above. 


\section{Appendix C}

\section{Sample Telephone/Face-to-face Interview Questions}

1. Preferred learning Practices

a) What was the biggest challenge for you in this online course? Why?

b) What strategies did you use to deal with the challenge?

c) How would you describe your learning style (preferred learning practice)?

d) How did you select which postings to read first? Why?

2. Relationship of Cultural Background to Preferred Learning Practices

a) Describe differences do you notice between the education system you had and that you had in the online course you were enrolled.

b) Describe how your MET online experiences were similar and or different from your past educational experiences.

c) What do you think of the socializing/mingling space on the course website? Do you think such a space is helpful for your learning?

d) Can you tell me why you chose to study in the online program?

3. What suggestions would you like to give for an online course (design and delivery)?

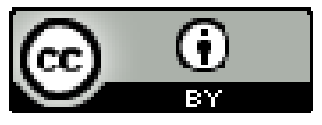

